\title{
Digital Work and High-Tech Wanderers: Three Theoretical Framings and a Research Agenda for Digital Nomadism
}

\author{
Blair Wang \\ UNSW Business School \\ Sydney, Australia \\ Email: blair.wang@unsw.edu.au

\section{Daniel Schlagwein} \\ Discipline of Business Information Systems \\ The University of Sydney Business School \\ Sydney, Australia \\ Email: schlagwein@sydney.edu.au
}

School of Information Systems and Technology Management

\section{Dubravka Cecez-Kecmanovic}

School of Information Systems and Technology Management UNSW Business School

Sydney, Australia

Email:dubravka@unsw.edu.au

\section{Michael C. Cahalane}

School of Information Systems and Technology Management UNSW Business School

Sydney, Australia

Email: m.cahalane@unsw.edu.au

\begin{abstract}
This paper presents a literature review and conceptual development of digital nomadism. Digital nomadism is characterised by mobile workers indefinitely travelling between different locations while continually fulfilling their work obligations. The emerging literature on digital nomadism is fragmented and primarily focused on digital nomads' lifestyles. There is comparatively less focus on theoretically framing digital nomadism into broader narratives in human history. In order to gain a holistic understanding, this paper reviews the limited literature on digital nomadism and expands to other relevant literatures on economy (e.g. traditional boundaries in business), culture (e.g. lifehacking), and technology (e.g. telework and digital communication). These three theoretical framings of digital nomadism enable this paper to identify the current state of knowledge relevant to digital nomadism and develop a research agenda.
\end{abstract}

Keywords: digital nomadism, digital work, telework, factors of production, lifehacking, prosumers 


\section{Introduction}

We live in a world in which digital technologies have transformed work. This is the phenomenon that the digital work research agenda seeks to understand (Orlikowski and Scott 2016). Digital work has been described in recent literature as a "grand challenge" for humanity (Colbert et al. 2016). It is such a challenge because it is accompanied by, for example, the loss of jobs as a result of more efficient production operations (Mrass et al. 2017), and reduced clarity about established work-related norms (Bordi et al. 2018). Nonetheless, as "the future of work itself" (Colbert et al. 2016), digital work presents an opportunity to improve human lives.

Digital nomadism is emerging as a growing segment of the digital work labour force. Digital nomads are teleworkers who have become so geographically mobile that they are free to work from almost anywhere in the world. They therefore choose not only to work from almost anywhere in the world but also live almost anywhere in the world, as "perpetual travellers" (Nash et al. 2018). Due to the digital nomads' defining characteristic of never staying in one place for too long, the total number of digital nomads is difficult to ascertain, in the rough order of magnitude of 200,000 to 500,000 (Schlagwein 2018). Moreover, due to the recency of digital nomadism, research has been scarce (Schlagwein 2018), and the research that does exist is fragmented and primarily focused on the digital nomad's lifestyle and psychological considerations such as self-actualisation (Müller 2016) and loneliness (Nash et al. 2018).

Yet digital nomadism is much more significant for humanity's historical narrative than simply another lifestyle. Digital nomadism is not only a new lifestyle option but indeed a new way of working and organising. Therefore, the research question we address is: How can we theoretically frame digital nomadism holistically as a new way of living, working, and organising?

We answer this research question based on an interdisciplinary literature review. Grounded in the literature review, we propose and discuss three theoretical framings of digital nomadism: digital nomadism as economic activity; digital nomadism as a cultural phenomenon; and digital nomadism as a new technology-enabled form of working and organising. These theoretical framings enable us to develop a holistic view of the state of knowledge relevant to digital nomadism. Consequently, we are able to propose a research agenda. Our contribution is relevant for academics interested in, and those seeking to explore, a holistic understanding of digital nomadism. Our contribution may also be beneficial for driving the strategic decisions of commercial organisations, and the policy directions of governing bodies, responding to digital nomadism and related concerns.

\section{Literature Review Method}

We operationalised the hermeneutic approach to literature review developed by Boell and CecezKecmanovic (2014). A hermeneutic literature review is characterised by interpretive, non-deterministic, non-replicable incremental discovery and understanding of literature. This was an important distinction for us, since there are many concepts and streams of literature that are related to digital nomadism but do not explicitly use that label, or even synonyms of that label. Keyword searches and systematic literature reviews would have therefore been unable to capture all relevant literature.

Accordingly, we started with a small set of highly relevant publications, and the resulting body of literature was formed through the conceptual relatedness of additional papers' contents, rather than the semantic similarity of additional papers' keywords. Although digital nomadism is still a very new phenomenon, it was possible - through a combination of initial keyword searches, subsequent interpretation, and citation tracking - to find a set of the most relevant articles (Müller 2016; Dobrinskaya 2016; Sutherland and Jarrahi 2017; Schlagwein 2018; Reichenberger 2018; Nash et al. 2018; Thompson 2018). The defining characteristic of this set is that they all explicitly use the term 'digital nomad' and provide an overview of digital nomadism from some perspective. Through multiple hermeneutic cycles, papers were discovered, read, re-read; and the direction of the literature search changed in response. The final set of 64 relevant papers includes 42 research papers (from academic journals and conferences, and chapters from edited volumes) and 22 papers from practitioners' literature and newspapers. We selected these papers based on their ability to shed light on the phenomenon of digital nomadism, even if the papers were not specifically written about digital 
nomadism. The reading and mapping/classifying of contents within these articles allowed for a critical assessment wherein three broad themes emerged; these are discussed in later sections of this paper.

Three dominant theoretical framings based on economy, culture, and technology were identified. This is shown in Figure 1 below. Topics such as digital (computer-mediated) communication and lifehacking emerged as the most relevant to explore under each broad theoretical framing. Subsequently, it was necessary to find papers specifically related to each of these topics. The papers under each topic are shown in Figure 1 around the circumference of the pie diagram in Figure 1 (only a sample of papers for each topic is shown so that the text is still readable). Papers published at academic outlets such as conferences and journals are shown in bold text whereas other sources such as newspaper articles and practitioner books are shown in italics. Referring to non-academic literature was appropriate because many concepts - for example, 'lifehacking' - emerged from such writing (e.g. Allen 2001; Ferriss 2007).

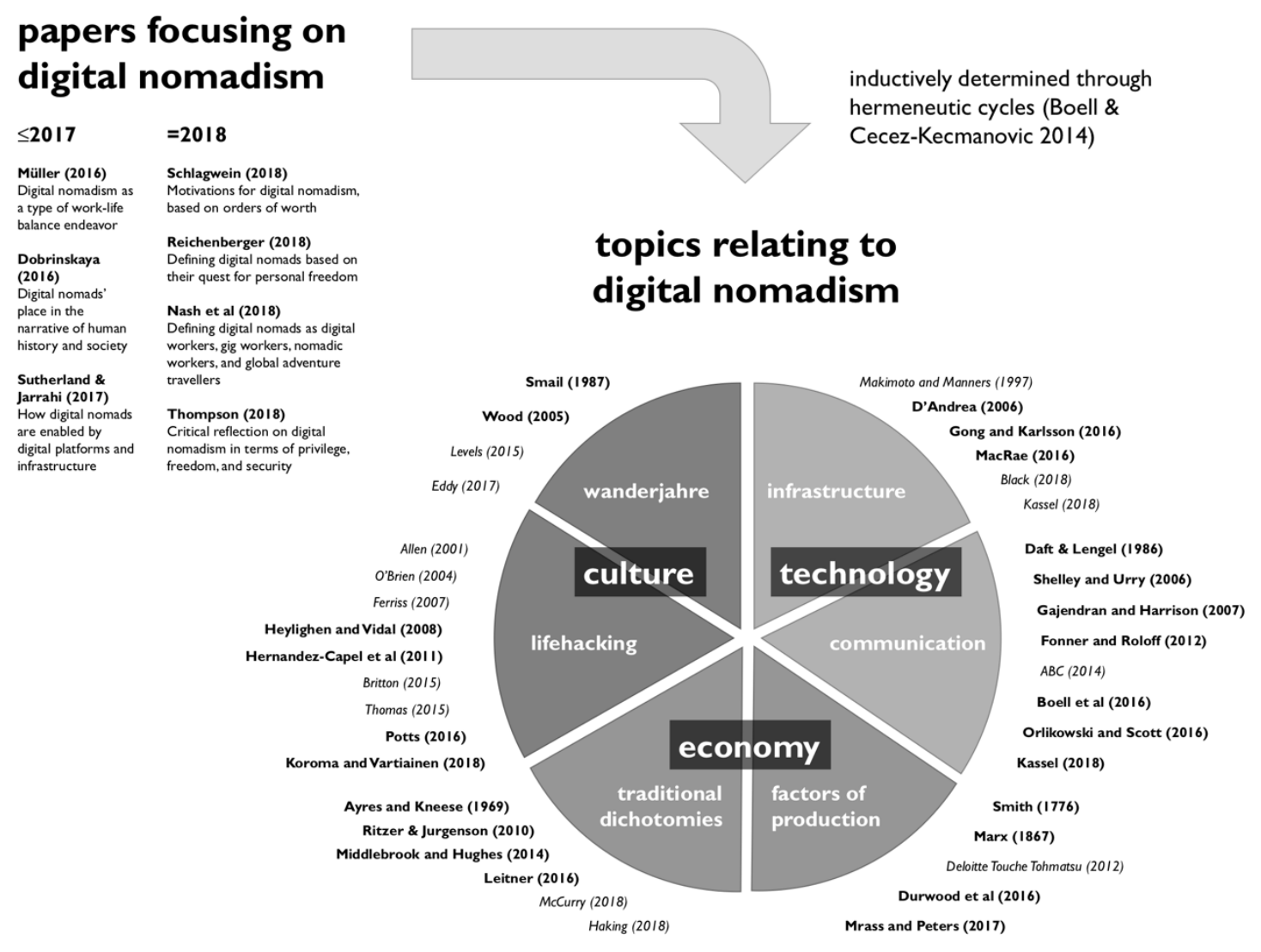

Figure 1. Outcome of the hermeneutic literature review of relevant literature.

\section{Theoretical Framing 1: Digital Nomadism as Economic Activity}

A portion of the reviewed literature suggests to theoretically frame digital nomadism as a new economic model. This view focuses on the underlying factors of production and sees digital work - such as that conducted by digital nomads - as a new form of economic activity. Digital nomadism exemplifies how this activity blurs the borders of old dichotomies such as production-or-consumption and customer-orcitizen. Businesses and governments, the majority of which are modelled on these established traditions, may find it helpful to adapt to such a conflation of previously separated concerns - a conflation that is not exclusive to digital nomads, but which is saliently exemplified by them.

\subsection{Digital Factors of Production}

There is a lack of consensus in the literature about what constitutes "digital work". Some propose the definition of digital work as the use of "digital tools to produce digital goods" (Durward et al. 2016; Mrass et al. 2017). Others propose a definition of digital work as essentially knowledge work; and thus, digital 
nomadism strictly as a type of knowledge work (Nash et al. 2018; Sutherland and Jarrahi 2017). Orlikowski and Scott (2016) propose a particularly broad definition wherein "work today always entails the digital; even where the work itself doesn't directly involve a computing device".

To understand the implications of digital nomadism as an example of digital work, it is important to first establish a clear definition of digital work. To this end, the hermeneutic cycles of the literature review took us to the conceptualisation of work at the heart of the modern economy: work as defined by its factors of production (Smith 1776), or as Marx (1867) labels them, the means of production. In either case, there are three factors of production: the labour (human effort involved in the work); the subject matter (the materials to which labour is applied, alternatively known as "land" or simply "subjects"); and the instruments (the reusable assets that assist human labour on the subject matter). Digital work, then, can be understood to be work in which digital technology has transformed factors of production. This can be seen in the case of the digital nomad. Labour is increasingly organised through distributed digital systems such as JIRA, Asana, and Google Calendar (Nash et al. 2018). Subject matter is increasingly digital data forming materials such as documents, statistics, audio/video recordings. Finally, instruments of work are now less defined by their mechanical configurations like the machines of the industrial revolution, and more defined by the bitstreams of digital data stored within the machine: ones and zeroes representing software that defines an instrument's ability to assist with work.

This definition is important for two reasons. Firstly, it provides a unifying explanation for the different conceptualisations of digital work: Orlikowski and Scott's (2016) definition refers to any work where digital technologies have transformed any factor of production. Their characterisation of modern work as "always entailing the digital" is therefore very reasonable. Meanwhile, the other definitions refer to only to work where digital technologies have at least transformed the subject matter, hence the characterisation of digital work as a subset of knowledge work. Secondly, understanding digital work as the digital transformation of factors of production clarifies the meaning of "disruptive" technologydriven phenomena such as digital nomadism. Such "disruptive" terminology is often misunderstood by key stakeholders in large organisations (Deloitte Touche Tohmatsu 2012). Clarifying "disruption" in terms originating in economics tradition, which such stakeholders are more likely to understand, is therefore likely to be helpful. An example of a research question arising from this could be: How do digital nomads, in their work, perform factors of production through different materialisations of digital data?

\subsection{Challenging Traditional Dichotomies}

Although they are both are essentially providers of services, the traditional conceptualisation of government is fundamentally different to that of private industry. Digital nomads, however, have been said to reduce the nation state to merely yet another provider of services, namely residence and citizenship. This has come about from digital nomads' ability to quickly move between jurisdictions; they effectively "hire and fire governments" (Crichton 2018). Even when digital nomads are residing within a state, the governing bodies may find it hard to exert as much influence as with more permanent residents. Digital nomadism leverages new technology platforms that are notoriously difficult to regulate. To obtain affordable and flexible accommodation arrangements, digital nomads have been known to rely on the grey-market housing service Airbnb (Nash et al. 2018; Sutherland and Jarrahi 2017). Existing literature has demonstrated that this service has significant implications for urban planning (Sans and Quaglieri 2016), and poses issues for regulation (Leshinsky and Schatz 2018; Edelman and Geradin 2016). Digital nomads' finances are also difficult for governments to track. In addition to moving funds between jurisdictions using payment-processing services such as PayPal and Transferwise (Nash et al. 2018), digital nomads are actively exploring the opportunities of cryptocurrencies such as Bitcoin (Sutherland and Jarrahi 2017), which cannot be regulated by governments using traditional monetary policy (Middlebrook and Hughes 2014).

In addition to the dichotomy of public versus private organisations, economics tradition has an established dichotomy of production versus consumption (Ayres and Kneese 1969). This has recently been challenged by examples such as self-crafted luxury goods (Kim and Kwon 2017), self-service and peer production (Ritzer and Jurgenson 2010), and tourism (Ateljevic 2000). The digital nomad joins this array of examples, being at the intersection of travel, leisure, and work (Müller 2016; Reichenberger 2018), becoming a hybrid of a travelling businessperson and a backpacker. The implications of these two very different social figures becoming one "flashpacker" is identified by Müller (2016) as being 
relatively uncharted in the literature. There is established literature in that digital nomads are similar to freelancers in the gig economy (Nash et al. 2018; Sutherland and Jarrahi 2017), wherein an individual is also an entrepreneur and indeed their own company, and hence required to manage personal brand image, pursue potential clients (Sutherland and Jarrahi 2017), and build client trust from afar despite a potentially very unusual working arrangement from the client's perspective (Leitner 2016). In this context, it is observed that not only are consumption and production interweaved in a digital nomad's schedule, but in some cases, consumption directly enables production, particularly as many digital nomads work in some sort of journalism (Nash et al. 2018) such as travel blogging, food and restaurant review, and video-blogging (vlogging). Even when consumption is not directly linked to production, the interleaving of the two creates a "conflation of perpetual travel and work", the consequences of which are not yet fully understood, though existing discourse about the challenges of work-life balance may be relevant (Haking 2018; Nash et al. 2018). Effectively, these "prosumers" - a portmanteau of professional and consumer (Ritzer and Jurgenson 2010) - blend typical consumption activities into their factors of production: they may repurpose consumer electronics as instruments of production, adapt the domain of their leisure as the subject matter of their work; and organise labour using the same platforms that they use to connect with friends and family, e.g. Facebook.

The status quo nonetheless remains that the established production/consumption dichotomy dominates strategy formulation. Governments still organise territory as residential versus commercial, and businesses still market products to either consumers (B2C) or other businesses (B2B). Yet those who have already adapted their strategy to move away from the dichotomy have been successful. A typical example is Apple, who sell the same products to both consumers and producers, and has reaped the benefits of doing so: their positive brand image is asserted across both segments, positioning them as a known supplier for prosumers (Gerhardt 2010). Meanwhile, Apple's competitor Dell, who in fact launched a "digital nomads" website in 2008 to promote their business laptops (Shiels 2008), continue to follow the producer/consumer dichotomy and have since abandoned said "digital nomads" website.

For the strategies of both businesses and governments, digital nomadism therefore represents both opportunities and threats. The new players like Airbnb and cryptocurrency management companies have capitalised on the digital nomadism phenomenon and profited accordingly. There is an opportunity for governments, too, since governments provide a safety net around workers through the provision of healthcare, aged care, and labour market policies governing workers' rights such as working hours, paid family leave, and workplace justice (e.g. outlawing unfair dismissal and unjust discrimination); being detached from government for the sake of freedom means sacrificing such things for the sake of freedom (Thompson 2018). Some governments proactively attract digital nomads and thus enhance their technology sector; notably the example of Estonia, through their e-residency programme (Gat 2018). However, this has not been without risk; a nomad-friendly business may stumble due to an unfavourable regulatory climate as with Airbnb in Japan (McCurry 2018), and a nomad-friendly government may stumble due to an unfavourable business climate as Estonia experienced with their local banks closing foreigners' business accounts (Vahtla 2018). As these circumstances unravel, so too will research opportunities emerge to better understand how service providers - including business operators, and indeed, even the government as a "hireable and fireable" provider of public services - might best respond. An example of a research question arising from this could be: How do traditional service providers, including government bodies, respond strategically to digital nomadism?

\section{Theoretical Framing 2: Digital Nomadism as a Cultural Phenomenon}

A portion of the reviewed literature suggests to theoretically frame digital nomadism as a cultural phenomenon. Digital nomads fly the proverbial flag of the lifehacking subculture popularised in the early mid-200os in a way that is reminiscent of the journeymen of old. It has yet to be fully understood how digital nomads' unique positioning within cultures impacts the way they work and do business with others. However, given the particularly salient cultural contexts in which digital nomads operate, and the uniquely-positioned concern that these cultural contexts have for work ethic and work-life balance, it would be quite likely that a deeper understanding of digital nomadism's cultural aspects would be beneficial for the strategic decision-making activities of businesses and governments. 


\subsection{Self-Actualisation and the Lifehacking Subculture}

Lifehacking is a recent subculture emerging in industrialised nations, closely associated with digital nomadism. Since the label "lifehacking" was first introduced by O'Brien (2004), lifehacking has come to refer to a worldview in which the challenges of one's life can be overcome using techniques analogous to hacking into a computer system. Accordingly, the lifehacking subculture is characterised by an affinity for autonomy, proactivity, and self-actualisation fulfilled through technical competence (Britton 2015; Thomas 2015). Digital nomads, who are characterised by self-actualisation (Müller 2016) and autonomy (Reichenberger 2018), are therefore closely affiliated with the lifehacking subculture. In particular, two prominent works (Potts 2010) from this subculture have become integral to the digital nomad's way of life (Schlagwein 2018): The Four Hour Work Week by Ferriss (2007), and Getting Things Done (GTD) by Allen (2001). The former popularised digital nomadism (Haking 2018; Schlagwein 2018), and the latter is a procedure for managing information overload - typical of what mobile workers such as digital nomads experience (Koroma and Vartiainen 2018; Sutherland and Jarrahi 2017) - which has become so influential that it has guided (Chait 2017) the design of the productivity software popular among digital nomads (Nash et al. 2018). The GTD procedure is notable for introducing the concept of "actionability" (Allen 2001), referring to the differentiation between, on one hand, information that represents the organisation of labour, and on the other hand, information used as instruments or subjects of labour.

There is relatively little literature exploring the impacts of the lifehacking subculture and the GTD procedure on work practices and outcomes in general, let alone in a digital nomadism context. The literature that does exist is primarily focused on the cultural significance of lifehacking (Thomas 2015), techniques to best implement GTD (Hernandez-Capel et al. 2011) and psychological outcomes of both GTD (Heylighen and Vidal 2008) and lifehacking in general (Potts 2010). One comment that has been made within the existing discourse, though, is that lifehacking is, at least conceptually, in opposition to the bureaucratic managerial practices originating in the industrial revolution (Potts 2010). This is implicit in the "hacking" within "lifehacking", that there is something to "hack" and challenge. As seen in, for example, their implications for the traditional structure of economy, digital nomads are indeed challenging many established institutions to fulfil their desires. Future research may do well to understand how the digital nomads' potentially counter-cultural philosophical position affects how they relate to potentially bureaucratic business partners such as large corporate clients and government bodies. The findings may have implications for the strategies adopted by both digital nomads and their business partners to bridge what may be a significant gap in work ethic and working culture. An example of a research question arising from this could be: How do the values and attitudes within the lifehacking subculture drive the trajectory of digital nomadism in relation to the role of work in one's life?

\subsection{Digital Nomadism as the New Wanderjahre}

Digital nomadism is not the first instance in human history in which post-agricultural societies have seen the rapid technology-enabled mobilisation of workers; an example of such a historical precedent can be seen in the Wanderjahre. In Medieval Europe, young tradespeople - essentially, the technology workers of that era - had a tradition of "taking to the road" (auf der Walz), travelling from town to town for a fixed period of two to three years (the Wanderjahre), carrying the tools of their craft, to enhance their personal and professional skills while free of personal attachments such as marriage (Eddy 2017). This tradition was spread to other European-influenced regions such as Australia, where the popular folk song Waltzing Matilda describes a particularly belligerent participant of this tradition (Davis 2013). These so-called "journeymen" (Wandergesellen) were established within society as parallel to the merchant class and often taken on board as apprentices by master craftspeople (Smail 1987). Though the Wanderjahre phenomenon disappeared during the course of the Industrial Revolution and the two World Wars, it has experienced a renaissance among tradespeople who have continued traditions such as initiation rites, strict community rules, and avoiding modern always-on connectivity such as mobile phones. Above all, what one modern journeyman said he appreciated most is the "freedom" afforded by his lifestyle (Eddy 2017).

There are strong parallels between digital nomadism and the Wanderjahre. Digital nomads are also typically young and of a particular profession that enables or encourages their travel, and they too value highly their exceptional freedom (Reichenberger 2018). They are also typically young and single, though 
not exclusively; there are also digital nomads that travel together with a partner or family (Wood 2005; Reichenberger 2018), and indeed, traditional nomadism is deeply rooted in "the priority of the nomad's family" (Dobrinskaya 2016). Yet the lack of attachments remains a persistent theme. Indeed, an assumption in the " 1 billion nomads by 2035 " forecast loosely extrapolated by Levels (2015) from public datasets is that the concept of the family will continue to deviate from traditional views such that by 2035 , less than $40 \%$ of society will be married. This would ostensibly enable the mobility that facilitates widespread digital nomadism.

Future research may investigate how, if at all, digital nomads are similar to their journeymen counterparts. It is, for example, not well understood whether digital nomads are usually committed to a nomadic lifestyle for their entire lives, or if their intention is usually to have their own short-term Wanderjahre before settling down into a more traditional lifestyle. If digital nomadism does continue to grow to be a significant portion of society, as some speculate it will, government policy and business strategies would do well to adapt likewise, just as master craftspeople adapted to journeymen by taking them on as apprentices. If the so-called information revolution is indeed as significant in humanity's historical narrative as the agricultural and industrial revolution, then the digital nomad, a key figure of this information revolution (Dobrinskaya 2016), is surely worth fully comprehending. An example of a research question arising from this could be: How could the trajectory of digital nomadism be better understood by examining its historical precedents?

\section{Theoretical Framing 3: Digital Nomadism as a Technology- Enabled Form of Working and Organising}

A portion of the reviewed literature suggests to theoretically frame digital nomadism as a new technology-enabled form of working and organising. This section presents the literature review of digital nomadism with respect to the underlying technological infrastructure, and the significance of technology for digital nomads' interpersonal communication. It will be seen that, despite some optimistic views about digital nomadism in recent times, present-day infrastructure has yet to fully enable digital nomadism as it was originally conceptualised and the computer-mediated communication that digital nomads employ has not always been found adequate. Nonetheless, the progress that has been hitherto made has enabled reduction in regional inequality and brought with it advances in digital working patterns that challenge established understandings of digital communication altogether, and business and governments may benefit richly from advancing in step with such progress.

\subsection{Telecommunications Infrastructure and Contradictions}

At its core, digital nomadism is enabled by advances in technology. Makimoto and Manners (1997), who first introduced the term "digital nomad", presented digital nomadism as a consequence of advances in electronics engineering, defined by the ability to connect any two points on the planet by "video link" to facilitate exchanges of "people, documents, and pictures". Two decades later, the proliferation of internet access has indeed enabled digital nomads to connect to distant points across the planet, and indeed often by video (Kassel 2018; Schlagwein 2018). Internet connection speeds are crucial since slow internet speeds limit all three factors of production. Organisation of labour (e.g. task lists) may not be conveyed due to outages; digital subject matter is not transferred through the digital supply chain; and even instruments may be rendered unusable due to the increasing preference for cloud-based software (Nash et al. 2018).

However, fast internet access is not consistently available. Though digital nomads favour "exotic" locations (Reichenberger 2018), being "exotic" is generally unhelpful for internet access, since infrastructure is fixed and requires large investments by companies and governments. Nomadism implies geographic mobility, but "basic physics" means that a wireless connection is almost always slower than a wired one (Gong and Karlsson 2016). There are hence certain "hot spots" for digital nomads, and thus present-day digital nomadism has yet to fully fulfil the original 1997 vision.

Nonetheless, the advances that have been hitherto made have already helped reduce regional inequality. In Australia, for example, there is currently an interest at a national level in reducing regional inequality (Parliament of Australia 2018). Digital nomadism has already demonstrated a potential to improve economic productivity in areas outside of capital cities, such as the Southern Tablelands (Black 2018) 
and Byron Bay (D'Andrea 2006). Other countries have seen similar regional rebalancing: in the neighbouring country of Indonesia, digital nomadism - enabled by the installation of fibre-optic internet connectivity just six years ago - has completely so much reshaped the former "village" of Ubud into a "diversifying international town" such that those once familiar with it no longer recognise it as such (MacRae 2016). Thus, examples of research questions that could be useful for strategic policysetting include: How does the tension between the affordances and constraints of current technology impact the work practices of digital nomads? How do infrastructure investments such as the NBN influence the decisions of digital nomads to move to regional areas? What are the impacts on regional areas when digital nomads do indeed move to them.

\subsection{Digital Collaboration and Communication}

Of all the factors of production that are being digitally transformed, the organisation of labour has often been characterised as the most problematic for digital work, being complex and requiring effective communication. This is particularly so when the organisation of labour is manifested as collaborative decision-making or as the sharing of advice (Boell et al. 2016). Yet computer-mediated communication (CMC) is exclusively how digital nomads communicate with their clients. The literature is characterised by a lack of consensus about the efficacy of CMC in such remote-working arrangements. Müller (2016) interprets Sheller and Urry (2006) regarding digital nomadism thusly: that, due to contemporary communication and collaboration systems, it is now the case that "physical presence of the participants is no longer necessary" (Müller 2016, p. 344). This is at odds with persistent claims (e.g., Brumma 2016; Fonner and Roloff 2012; Gajendran and Harrison 2007; Ogara et al. 2014) that CMC and virtual presence are still inferior to face-to-face communication and physical presence, particularly in teleworking contexts of which digital nomadism is a specific example.

Nevertheless, digital nomads have been able to survive despite the apparent constraints of their exclusively digital communication. One possible explanation is that traditional perspectives such as media richness theory (Daft and Lengel 1986) and media naturalness theory (Kock 2005) are excessively focused on the channel of communication and whether that channel is inherently "rich"/"natural" or "lean"/"noisy". Communication is, in that instance, a matter of accurately representing an objective external reality. In reality, the digital nomad employs a vast ecosystem of technology platforms enabling digital nomads to conduct their work (Nash et al. 2018): profession-specific tools (GitHub, Adobe Creative Cloud), general tools (Slack, Skype), productivity aids (Trello, Asana), and online communities with which to seek new work (LinkedIn, Medium, Upwork, Remoteok) or assist one another (NomadList, Hacker Paradise; Twitter, meetup.com, Facebook). In this instance, communication is about co-creating a new digital reality rather than recreating an existing external reality. Authors such as Nash et al. (2018) and Orlikowski and Scott (2016) argue that best explanation for this phenomenon is the sociomateriality worldview with its pillars of performativity (reality is co-created rather than captured) and entanglement (the inseparable intra-acting of people and technology in ever-evolving "assemblages"). Future research may investigate the sociomateriality of digital nomadism to understand how digital nomads seem to have achieved what literature often characterises as highly impractical: work entirely remotely with no face-to-face communication with business partners. This theoretical discourse has significant implications for business strategies and policy-setting. The business case for infrastructure investments such as Australia's National Broadband Network (NBN) is often framed primarily in terms of video conferencing and being able to recreate face-to-face communication, and the objection is often framed in terms of whether video conferencing and recreating face-to-face communication is really the main objective (NBN Co 2017; ABC 2014). A paradigm shift may help these stakeholders better articulate, and thus leverage, the benefits of the technology. An example of a research question arising from this could be: How do digital nomads perform effective communication in the digital space to cope with their limited ability to conduct face-to-face business?

\section{Discussion}

We have presented the state of current understanding about digital nomadism. Although prior studies have considered in depth the digital nomads' personal lifestyles, there has been relatively little in-depth consideration of how digital nomads fit into broader historical narratives, particularly regarding how they work, and how this may relate to the strategic positioning of businesses and governments. We have explicated this as six topics segmented into the three broad theoretical framings of the economic, the 
cultural, and the technological. We have made a number of contributions to Information Systems (IS) research in relation to each of these topics by highlighting hitherto relatively neglected considerations and setting a research agenda for them:

- To better understand digital nomadism as an economic phenomenon, further develop a theoretical framework of the digital enactment of factors of production, and further investigate the consequences of blurring boundaries of public/private and consumption/production;

- To better understand digital nomadism as a cultural phenomenon, investigate the influences of the lifehacking subculture and its related concepts (e.g. GTD) and explicate the fundamental similarities between digital nomadism and the traditional Wanderjahre with respect to the future of the digital nomad and the digital nomad's life plan;

- To better understand digital nomadism as a technological phenomenon, investigate the impact of the constraints of the underlying technological including telecommunications infrastructure and the configuration of computer-mediated communication platforms.

Our contribution is constrained by the relative recency of the digital nomadism phenomenon and the consequently relatively small number of papers to consider. The phenomenon is very likely to continue to shift in unpredictable ways that, as with the current state, call for an interdisciplinary approach as well as multiple philosophical backgrounds. For example, a deeper consideration of the socio-cultural issues may likely require insights from traditions in the study of culture such as ethnographic principles; whereas a deeper consideration of the technological issues may likely require further insights from the literature on, for example, digital transformation; and a deeper consideration of the economic issues is very likely to require a serious consideration of the critical analysis of, for example, Marx (1867) in relation to modern capitalism and how this transposes into the digital era, for example, the contestation and reconfiguration of established orders of worth and institutional logics (Schlagwein 2018).

\section{Conclusion}

Digital nomads are teleworkers whose extreme geographic mobility allows them to work and live from anywhere, enabled by the digitising of their factors of production. They therefore choose to work from everywhere, living a life of ongoing interleaved work and travel. We may understand digital nomadism as an example of economic activity, wherein digital nomads challenge traditional dichotomies such as production/consumption and government/business. We may understand digital nomadism as a cultural phenomenon arising from lifehacking subculture and fulfilling a modern analogue of the wandering journeymen of old. We may understand digital nomadism as an example of limited but effective technological progress, wherein underlying infrastructure and subsequent digital communications are imperfect but have allowed significant progress to be made in terms of regional inequality and flexible working. As we continue to refine our understanding of digital nomadism, we open up many possibilities for businesses and governments to respond strategically to digital nomadism.

\section{References}

ABC. 2014. "National Broadband Network (NBN) cost-benefit analysis released". ABC News, http://www.abc.net.au/news/2014-08-27/nbn-cost-benefit-analysis-released/5698838 Retrieved 4 July 2018.

Allen, D. 2001. Getting Things Done: The Art of Stress-Free Productivity. Penguin.

Ateljevic, I. 2000. "Circuits of tourism: Stepping beyond the 'production/consumption' dichotomy," Tourism Geographies (2:4), pp. 369-388.

Ayres, R. U., and Kneese, A. V. 1969. "Production, Consumption, and Externalities," The American Economic Review (59:3), pp. 282-297.

Black, M. 2018. "Far-flung farm the right fit for young digital nomad”. ABC News, 1 June.

Boell, S. K., and Cecez-Kecmanovic, D. 2014. "A Hermeneutic Approach for Conducting Literature Reviews and Literature Searches," Communications of the AIS (34), pp. 257-286.

Boell, S. K., Cecez-Kecmanovic, D., and Campbell, J. 2016. "Telework paradoxes and practices: the importance of the nature of work," New Technology, Work and Employment (31), pp. 114-131. 
Bordi, L., Okkonen, J., Mäkiniemi, J.-P., and Heikkilä-Tammi, K. 2018. "Communication in the Digital Work Environment: Implications for Wellbeing at Work," Nordic Journal of Working Life Studies (8:S3).

Britton, M. 2015. "Lifehacking," in YouthNation: Building Remarkable Brands in a Youth-Driven Culture. John Wiley \& Sons.

Brumma, F. 2016. "Telework is Work: Navigating the New Normal," in Cornell HR Review. Cornell University.

Chait, D. 2017. "The GTD Approach To Maximizing Productivity With Trello," in: Trello Blog.

Colbert, A., Yee, N., and George, G. 2016. "The digital workforce and the workplace of the future," Academy of Management Journal (59:3), pp. 731-739.

Crichton, D. 2018. "Digital nomads are hiring and firing their governments". TechCrunch, 18 February. https://techcrunch.com/2018/02/17/digital-nomads-are-hiring-and-firing-theirgovernments/ Retrieved 15 May 2018.

D'Andrea, A. 2006. "Neo-Nomadism: A Theory of Post-Identitarian Mobility in the Global Age," Mobilities (1), pp. 95-119.

Daft, R. L., and Lengel, R. H. 1986. “Organizational Information Requirements, Media Richness and Structural Design,” Management Science (32:5), pp. 554-571.

Davis, M. 2013. “Der Waltzing Matilda”. SBS News, 23 August. https://www.sbs.com.au/news/derwaltzing-matilda Retrieved 23 August 2013.

Deloitte Touche Tohmatsu. 2012. Digital disruption: Short fuse, big bang?

Dobrinskaya, D. E. 2016. "Nomadic lifestyle in the network society: sociological aspect," ConnectUniversum (3).

Durward, D., Blohm, I., and Leimeister, J. M. 2016. "Crowd Work," Business \& Information Systems Engineering (58:4), pp. 281-286.

Eddy, M. 2017. "Cleaving to the Medieval, Journeymen Ply Their Trades in Europe". The New York Times.

Edelman, B., and Geradin, D. 2016. "Efficiencies and Regulatory Shortcuts: How Should We Regulate Companies like Airbnb and Uber?," Stanford Technology Law Review (19:2), pp. 293-328.

Ferriss, T. 2007. The 4-hour work week: Escape the 9-5, live anywhere and join the new rich.

Fonner, K. L., and Roloff, M. E. 2012. "Testing the Connectivity Paradox: Linking Teleworkers' Communication Media Use to Social Presence, Stress from Interruptions, and Organizational Identification," Communication Monographs (79:2), pp. 205-231.

Gajendran, R. S., and Harrison, D. A. 2007. "The Good, the Bad, and the Unknown About Telecommuting: Meta-Analysis of Psychological Mediators and Individual Consequences," Journal of Applied Psychology (92:6), pp. 1524-1541.

Gat, O. 2018. "Estonia Goes Digital: Residents of the tiny Baltic nation are going all in on technogovernance," World Policy Journal (35:1), pp. 108-113.

Gerhardt, W. 2010. Prosumers Essential to Accelerating New Markets for Service Providers.

Gong, S., and Karlsson, M. 2016. "Pushing the Wireless Data Rate to the Internet Speed," IEEE Access (4), pp. 8787-8792.

Haking, J. 2018. "Digital Nomad Lifestyle: A field study in Bali." student thesis, KTH Royal Institute of Technology (Sweden).

Hernandez-Capel, C., Belmonte-Carmona, A., Roca-Piera, J., and Alvarez-Bermejo, J. A. 2011. "Integrated architecture to track and organize tasks in corporations and institutions," International Conference on Next Generation Web Services Practices (NWeSP) (7).

Heylighen, F., and Vidal, C. 2008. "Getting Things Done: The Science behind Stress-Free Productivity," Long Range Planning (41:6), pp. 585-605.

Kassel, N. 2018. "Ultimately, it's freedom: The young digital nomads descending on Bali for a poolside career". ABC News.

Kim, H. Y., and Kwon, Y. J. 2017. "Blurring production-consumption boundaries: Making my own luxury bag," Journal of Business Research (74), pp. 120-125.

Kock, N. 2005. "Media Richness or Media Naturalness? The Evolution of Our Biological Communication Apparatus and Its Influence on Our Behavior Toward E-Communication Tools," IEEE Transactions on Professional Communication (48:2), pp. 117-130.

Koroma, J., and Vartiainen, M. 2018. "From Presence to Multipresence: Mobile Knowledge Workers' Densified Hours," The New Normal of Working Lives), pp. 171-200.

Leitner, T. M. 2016. Corporate design principles to integrate digital nomads in post-bureaucratic organisations. student thesis, Fundacao Getulio Vargas.

Leshinsky, R., and Schatz, L. 2018. ““I Don’t Think My Landlord Will Find Out:” Airbnb and the Challenges of Enforcement," in Urban Policy and Research. 
Levels, P. 2015. “There will be 1 billion digital nomads by 2035”, presented at the DNX Global Digital Nomad Conference, Berlin (Germany).

MacRae, G. 2016. "Community and cosmopolitanism in the new Ubud," Annals of Tourism Research (59), pp. 16-29.

Makimoto, T., and Manners, D. 1997. Digital Nomad.

Marx, K. 1867. Das Kapital.

McCurry, J. 2018. “Tourism pollution: Japanese crackdown costs Airbnb \$10m”. The Guardian.

Middlebrook, S. T., and Hughes, S. J. 2014. "Regulating Cryptocurrencies in the United States: Current Issues and Future Directions," William Mitchell Law Review (40:2).

Mrass, V., Li, M. M., and Peters, C. 2017. "Towards a taxonomy of digital work”, presented at the European Conference on Information Systems, Guimarães (Portugal), 5-10 June 2017.

Müller, A. 2016. "The digital nomad: Buzzword or research category?,” Transnational Social Review (6:3).

Nash, C., Jarrahi, M. H., Sutherland, W., and Phillips, G. 2018. "Digital nomads beyond the buzzword: Defining digital nomadic work and use of digital technologies," Lecture Notes in Computer Science (10766), pp. 207-217.

NBN Co. 2017. Free video conferencing options for business.

O'Brien, D. 2004. "Life hacks: Tech secrets of overprolific alpha geeks," Emerging Technology Conference, San Diego (USA). https://www.youtube.com/watch?v=NhbqrxmUlQg Retrieved 15 May 2018.

Ogara, S. O., Koh, C. E., and Prybutok, V. R. 2014. "Investigating factors affecting social presence and user satisfaction with Mobile Instant Messaging," Computers in Human Behavior (36), pp. 453-459.

Orlikowski, W. J., and Scott, S. A. 2016. "Digital Work: A Research Agenda," in A Research Agenda for Management and Organization Studies. pp. 88-96.

Parliament of Australia. 2018. "Regional Inequality in Australia." https://www.aph.gov.au/Parliamentary Business/Committees/Senate/Economics/Regional Inequality in Australia Retrieved 4 July 2018.

Potts, T. 2010. "Life Hacking and Everyday Rhythm," in Geographies of Rhythm: Nature, Place, Mobilities and Bodies.

Reichenberger, I. 2018. "Digital nomads - a quest for holistic freedom in work and leisure," Annals of Leisure Research (21:3).

Ritzer, G., and Jurgenson, N. 2010. "Production, Consumption, Prosumption: The nature of capitalism in the age of the digital "prosumer'," Journal of Consumer Culture (10:1), pp. 13-36.

Sans, A. A., and Quaglieri, A. 2016. Unravelling airbnb: Urban perspectives from Barcelona.

Schlagwein, D. 2018. "Escaping the Rat Race: Justifications in Digital Nomadism," European Conference on Information Systems (26).

Sheller, M., and Urry, J. 2006. "The new mobilities paradigm," Environment and Planning A: Economy and Space (38:2), pp. 207-226.

Shiels, M. 2008. "Digital nomad drives laptop sales”. BBC News.

Smail, J. 1987. "New Languages for Labour and Capital: The Transformation of Discourse in the Early Years of the Industrial Revolution," Social History (12:1), pp. 49-71.

Smith, A. 1776. The Wealth of Nations.

Sutherland, W., and Jarrahi, M. H. 2017. "The Gig Economy and Information Infrastructure: The Case of the Digital Nomad Community," Proceedings of the ACM on Human-Computer Interaction (1).

Thomas, M. A. 2015. Life hacking: a critical history, 2004-2014.

Thompson, B. Y. 2018. "Digital Nomads: Employment in the Online Gig Economy," Glocalism: Journal of Culture, Politics and Innovation (1).

Vahtla, A. 2018. "E-Residency program under threat as banks closing foreigners' bank accounts". Eesti Rahvusringhääling.

Wood, M. 2005. "Nomad Aesthetics and the Global Knowledge Economy," Tamara: Journal for Critical Organization Inquiry (3:4), pp. 50-64. 


\section{Acknowledgements}

One of the co-authors of this paper is conducting this research with the assistance of the Commonwealth of Australia through an Australian Government Research Training Program Scholarship.

\section{Copyright}

Copyright: (C) 2018 authors. This is an open-access article distributed under the terms of the Creative Commons Attribution-NonCommercial 3.0 Australia License, which permits non-commercial use, distribution, and reproduction in any medium, provided the original author and ACIS are credited. 